\title{
SYNTHESIS OF [18F]GBR 12909, A DOPAMINE REUPTAKE INHIBITOR
}

Michael S. Haka and Michael R. Kilbourn

Division of Nuclear Medicine, Department of Internal Medicine, University of Michigan Medical School, Ann Arbor, MI 48109

\section{SUMMARY}

Preparation of no-carrier-added fluorine-18 labeled GBR 12909 (1-[2-(bis(4fluorophenyl)methoxy)ethyl]-4-(3-phenylpropyl)piperazine), a specific and high affinity inhibitor of dopamine reuptake, is described. 4-Fluoro-4'-[18F]fluorobenzophenone was prepared by [ $18 \mathrm{~F}]$ fluoride ion substitution of the corresponding trimethylammonium trifluoromethanesulfonate salt. The [18F]benzophenone was reduced to the benzhydrol, chlorinated, then used to alkylate 1-(2-hydroxyethyl)-4-(3-phenylpropyl)piperazine to yield [18F]GBR 12909 in high specific activity (>2000 Ci/mmol) and overall yields of $10-16 \%$ (corrected, 140 min synthesis).

KEY WORDS: $\quad$ Fluorine-18, dopamine, [18F]GBR 12909, uptake

\section{INTRODUCTION}

We have recently reported the synthesis of [18F]GBR 13119 (Fig. 1), a specific, high affinity inhibitor of the dopamine reuptake system $(1,2)$. Although suitable for extensive animal use, the application of this radiotracer to human studies proved troublesome, due to the lack of pharmacological and toxicological data. A closely related compound, GBR 12909 (1-[2-(bis(4-fluorophenyl)methoxy)ethyl]-4-(3phenylpropyl)piperazine), is in clinical trials and has been extensively studied as to its pharmacology and toxic properties in both animals and humans $(3,4)$. We describe here the synthesis of GBR 12909 (Fig 1) in fluorine-18 form suitable for human use. 


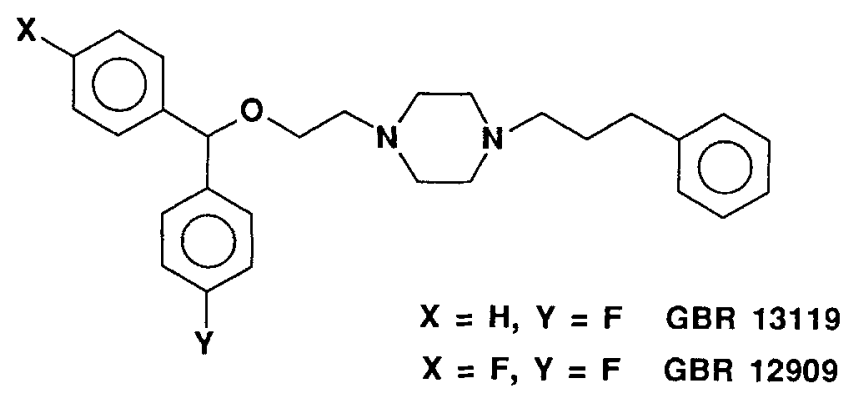

Figure. 1

\section{EXPERIMENTAL}

Materials and Methods. The following chemicals were obtained from the indicated sources and used without further purification: thionyl chloride, lithium aluminum hydride (1 $\mathrm{M}$ in THF), carbon disulfide, mesitylene, methyl trifluoromethanesulfonate, N,N-dimethylaniline, $\operatorname{tin}(I V)$ chloride, and 4fluorobenzoyl chloride from Aldrich Chem Co. N-(2-Hydroxyethyl)-N-(3-phenylpropyl)piperazine was prepared per literature methods (5). High specific activity (approx. 50,000 Ci/mmol) $\left[{ }^{18} \mathrm{~F}\right]$ fluoride ion was prepared by proton bombardment of [180]water (95-99\% enrichment, Isotec) as previously described (6). Thin layer chromatography was done using plastic-backed silica gel plates (Merck), and preparative layer chromatography using $2 \mathrm{~mm}$ silica gel plates (Merck). Melting points were determined with a Mel-Temp apparatus and are reported uncorrected. NMR spectra were done using a Bruker WM360 spectrometer, and mass spectra were determined using a VG Instruments Model 70-250S mass spectrometer utilizing fast atom bombardment with 3-nitrobenzyl alcohol as matrix.

4-Fluoro-4'-N,N-dimethylaminobenzophenone (1). A $250 \mathrm{ml}$ 3-neck round bottom flask was equipped with a mechanical stirrer, a reflux condenser with $\mathrm{CaCl}_{2}$ drying tube, and a dropping funnel, and an argon atmosphere introduced. To this were added $21.5 \mathrm{~g}(82.5 \mathrm{mmol})$ of $\mathrm{SnCl}_{4}$ and $100 \mathrm{ml}$ of dry $\mathrm{CS}_{2}$. The mixture was cooled to 5 ${ }^{\circ} \mathrm{C}$ (ice-water) and vigorously stirred while $\mathrm{N}, \mathrm{N}$-dimethylaniline $(5.0 \mathrm{~g}, 41.26 \mathrm{mmol})$ was added dropwise over $10 \mathrm{~min}$. The dropping funnel was then washed with $10 \mathrm{ml}$ of 
$\mathrm{CS}_{2}$. To the yellow slurry was then added 4-fluorobenzoyl chloride (6.54 $\mathrm{g}, 41.26 \mathrm{mmol}$ ) dropwise over 15 minutes. After addition was complete, the mixture was warmed to room temperature and finally refluxed for one hour. The now dark black-green mixture was cooled to $5^{\circ} \mathrm{C}$ and ice $(50 \mathrm{~g})$ and then water $(100 \mathrm{ml})$ added; a dark green oil separated at this point. Steam was then passed through the mixture to remove the carbon disulfide and unreacted $\mathrm{N}, \mathrm{N}$-dimethylaniline. The residue was cooled to $5 \mathrm{o}^{\circ} \mathrm{C}$ and filtered to yield a dark blue-green solid. The solid was suspended in $200 \mathrm{ml}$ of water at $50{ }^{\circ} \mathrm{C}$ and then filtered, and this process was repeated twice. The remaining green solid was washed with water and cold methanol $(100 \mathrm{ml})$ to yield $3.0 \mathrm{~g}$ of crude product.

The crude material was dissolved in $100 \mathrm{ml}$ of chloroform and filtered. The solution was washed with $3 \times 35 \mathrm{ml}$ portions of $7.5 \%$ aqueous hydrogen peroxile containing $1.0 \mathrm{~g} \mathrm{NaOH}$ per portion. Finally, the chloroform solution was washed with $100 \mathrm{ml}$ water, dried $\left(\mathrm{MgSO}_{4}\right)$, and evaporated to give $0.5 \mathrm{ml}$ of a yellow crystalline product. This was dissolved in $10 \mathrm{ml}$ of acetone, heated to reflux, and filtered hot. The filtrate was then allowed to cool overnight. The yellow crystals of 4-fluoro-4'-N,Ndimethylaminobenzophenone were collected by filtration. TLC showed a small impurity, which was separated by silica gel preparative layer chromatography $(2 \mathrm{~mm}$ silica gel, $\mathrm{CH}_{2} \mathrm{Cl}_{2}$ ) to afford $600 \mathrm{mg}$ ( $6 \%$ yield) of the desired 4-fluoro-4'-N,Ndimethylaminobenzophenone 1: m.p. 107-109 oC; ${ }^{1} \mathrm{H} \mathrm{NMR}\left(\mathrm{CDCl}_{3}\right) \delta 2.97(\mathrm{~s}, 6 \mathrm{H}$, $\left.\mathrm{N}\left(\mathrm{CH}_{3}\right)_{2}\right), 6.57-6.59$ (d, $2 \mathrm{H}, \mathrm{ArH}$ ortho to amine), 7.0-7.05 (dd, $2 \mathrm{H}, \mathrm{ArH}$ ortho to fluorine), 7.64-7.68 (m, $4 \mathrm{H}$, ArH ortho to carbonyl).

4-Fluoro-4'-N,N,N-trimethylammoniobenzophenone (2). Under an Ar atmosphere, methyltrifluoromethanesulfonate $(63.3 \mu \mathrm{l}, 0.56 \mathrm{mmol})$ was added to a solution of dimethylaminobenzophenone $1(127 \mathrm{mg}, 0.523 \mathrm{mmol})$ in $10 \mathrm{ml} \mathrm{of} \mathrm{CH}_{2} \mathrm{Cl}_{2}$. The yellow solution was stirred overnight, then diethyl ether added. The white precipitate which formed was collected and recrystallized to give the desired trimethylammonium salt 2: yield $85 \mathrm{mg}, 40 \%$; m.p. $84-86^{\circ} \mathrm{C}$; Mass spec (FAB) m/z 258 (positive ion, calcd for $\mathrm{C}_{16} \mathrm{H}_{17} \mathrm{NFO}^{+}, 258$ ) $\mathrm{m} / \mathrm{z} 149$ (negative ion, calcd for $\mathrm{CF}_{3} \mathrm{SO}_{3}{ }^{-}, 149$ ). Analysis: Calcd for $\mathrm{C}_{17} \mathrm{H}_{17} \mathrm{NO}_{4} \mathrm{~F}_{4} \mathrm{~S} \cdot 1 / 2 \mathrm{H}_{2} \mathrm{O}, \mathrm{C}, 49.04 ; \mathrm{H}, 4.36 ; \mathrm{N}, 3.36$. Found: $\mathrm{C}, 48.96$; $\mathrm{H}, 4.96 ; \mathrm{N}, 3.24$. 
4- $\left[{ }^{18}\right.$ FlFluoro-4'-fluorobenzophenone (3). To a solution of no-carrier-added

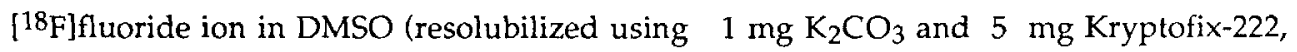
as per previous methods (1)) was added $1 \mathrm{mg}$ of trimethylammonium salt 2 . The solution was heated at $155{ }^{\circ} \mathrm{C}$ for $20 \mathrm{~min}$, then cooled and an aliquot removed. The aliquot was diluted with water and the product extracted into diethyl ether: yields 60$94 \%$, TLC silica gel $\left(8 / 2\right.$ pentane /ether) $R_{f}=0.57$. The bulk of the reaction was not worked up but used in the next step.

4- ${ }^{18}$ F]Fluoro-4'-fluorobenzhydrol (4). The solution of crude [18F]benzophenone 3 in DMSO was cooled (0-5 ${ }^{\circ} \mathrm{C}$, ice-water) and lithium aluminum hydride $(0.1 \mathrm{ml}, 100$ $\mu \mathrm{mol}$ ) added via syringe. After $1 \mathrm{~min}$, the reaction was quenched by dropwise addition of $2 \mathrm{~N} \mathrm{HCl}$, and then $10 \mathrm{ml}$ of $2 \mathrm{~N} \mathrm{HCl}$ added and the aqueous mixture passed through a C18 Sep-Pak. The Sep-Pak was washed with water $(5 \mathrm{ml})$, then the product eluted with $2 \mathrm{ml}$ of $\mathrm{CH}_{2} \mathrm{Cl}_{2}$ which was then dried $\left(\mathrm{MgSO}_{4}\right)$. Yield $55-85 \%$ (from [ ${ }^{18} \mathrm{~F}$ ]fluoride); TLC (silica gel, $7 / 3$ hexane/ethylacetate) $R_{f}=0.16$.

4-[18 F]Fluoro-4'-fluorobenzhydryl chloride (5). The solution of $\left[{ }^{18} \mathrm{~F}\right]$ benzhydrol 4 was evaporated (slow $\mathrm{N}_{2}$ flow) and $300 \mu$ lof $\mathrm{SOCl}_{2}$ added. The solution was heated (100 ${ }^{\circ} \mathrm{C}$, closed vessel) for $20 \mathrm{~min}$, cooled, and the thionyl chloride evaporated to yield crude chloride 5; yields 80-95\% (from alcohol 4); TLC (silica gel, 7/3 hexane/ethylacetate) $R_{\mathrm{f}}$ $=0.50$.

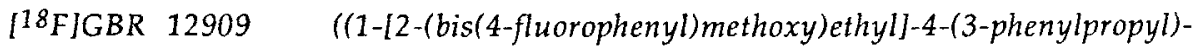
piperazine). To the residue of $\left[{ }^{18} \mathrm{~F}\right]$ chloride 5 was added $10 \mathrm{mg}$ of $\mathrm{N}$-(2-hydroxyethyl)-N(3-phenylpropyl)piperazine in $50 \mu 1$ mesitylene, and the solution heated at $155{ }^{\circ} \mathrm{C}$ for 25 min. The vessel was cooled and the brown oil dissolved in $0.5 \mathrm{ml}$ of methanol. The methanol was then diluted with $10 \mathrm{ml}$ of water and passed through a C18 Sep-Pak. The Sep-Pak was washed with water, then the products eluted with $10 \mathrm{ml}$ of pentane. The pentane was dried $\left(\mathrm{MgSO}_{4}\right)$ and then passed through a silica gel Sep-Pak. The silica gel was washed with $2 \times 20 \mathrm{ml}$ of $1 / 1$ pentane $/ \mathrm{CH}_{2} \mathrm{Cl}_{2}$, and the product [18F]GBR 12909 eluted with $10 \mathrm{ml}$ of $5 \%$ methanol $/ \mathrm{CH}_{2} \mathrm{Cl}_{2}$. Yield of condensation reaction 25-60\%; TLC (silica gel, 95/5 $\mathrm{CH}_{2} \mathrm{Cl}_{2} /$ methanol) $\mathrm{R}_{\mathrm{f}}=0.31$; HPLC, Phenomenex C18 column, $0.45 \times 15$ 
$\mathrm{cm}, 60 / 40$ acetonitrile $/ 0.065 \mathrm{M} \mathrm{NH}_{4} \mathrm{OAc}$ ( $3 \mathrm{ml}$ tetrahydrofuran/liter water), $2 \mathrm{ml} / \mathrm{min}$ flow: $G B R$ 12909, $R_{t}=14.0 \mathrm{~min}$; piperazine, $R_{t}=3.5 \mathrm{~min}$. Product identity was confirmed by comparison to a known standard of GBR 12909 obtained from NOVO Industri, A/S (also available from Research Biochemicals Incorporated). Overall yields of [18F]GBR12909 ranged from 10-16\% (corrected for decay) with a synthesis time of $120-$ $140 \mathrm{~min}$. For biological studies the product was prepared for injection by evaporation of the organic solvent and dissolution in dilute acidic saline ( $\mathrm{pH} 5.5$ ).

\section{RESULTS AND DISCUSSION}

The synthesis of [18F]GBR 12909 follows the same synthetic route as we have previously developed for [18F]GBR 13119 (1). The necessary precursor, 4-fluoro-4trimethylammoniumbenzophenone triflate (2), was prepared by the method shown in Figure 2. Friedel-Crafts acylation of N,N-dimethylaniline with 4-fluorobenzoyl

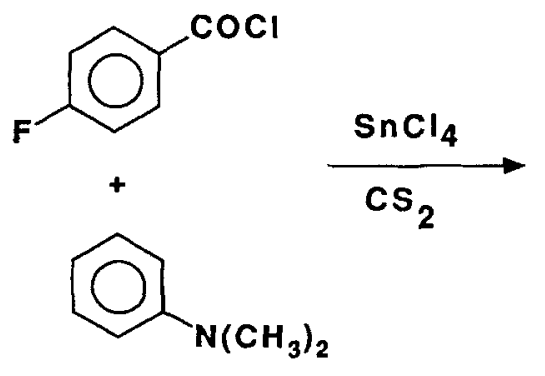<smiles>CN(C)c1ccc(C(=O)c2ccc(F)cc2)cc1</smiles>

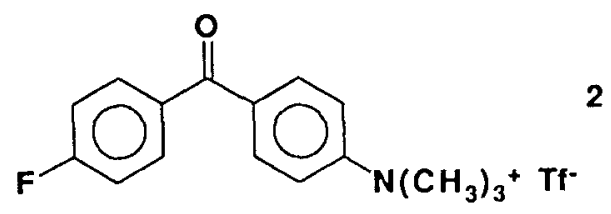

Fig. 2

chloride gave multiple acylation products, from which the desired 4-fluoro-4'-N,Ndimethylaminobenzophenone $\mathbf{1}$ was isolated by crystallization and silica gel preparative layer chromatography. Although this provided a direct route to the tertiary amine 1, the yield was very low and alternative syntheses of 1 were examined. The use of anhydrous aluminum chloride as the Friedel-Crafts catalyst gave, instead of the 
desired mono-acylation product 1, a good yield (35\%) of a product identified by NMR $\left({ }^{1} \mathrm{H}\right.$ and $\left.{ }^{13} \mathrm{C}\right)$ and mass spectroscopy $\left(\mathrm{m} / \mathrm{e} 365, \mathrm{M}^{+}\right)$as a di-acylation product. This bisacylation product was obtained even in the presence of excess $\mathrm{N}, \mathrm{N}$-dimethylaniline. At this time we are uncertain as to whether the second acyl group has added ortho- or meta- to the dimethylamine substituent; this unusually facile bis-acylation reaction is under further study. An alternative route using Friedel-Crafts acylation of acetanilide, followed by hydrolysis to the primary amine and methylation, was attempted but did not prove advantageous, due to unexpected difficulties in the hydrolysis step.

The N,N-dimethylamine 1 isolated by chromatography was then alkylated (methyl trifluoromethanesulfonate) to give the trimethylammonium salt 2 , which was separated from traces of the starting material by recrystallization.<smiles>CN(C)c1ccc(C(=O)c2ccc(F)cc2)cc1</smiles>

2

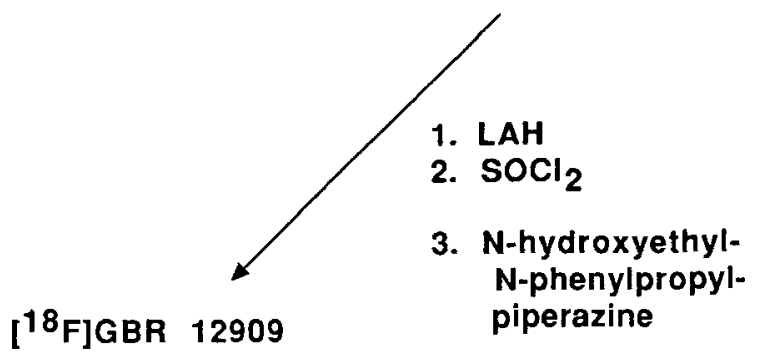

Fig 3

Reaction of the trimethylammonium salt 2 with NCA $\left[{ }^{18}\right.$ F]fluoride ion proceeded smoothly to give the benzophenone 3 (Fig. 3) in 60-94\% yields (no attempts were made to isolate the other possible product, arising from isotopic exchange of fluorines). Reduction, chlorination, and condensation with N-(2-hydroxyethyl)-N-(3phenylpropyl)piperazine to give [18F]GBR 12909 proceeded analagously to the synthesis of [ ${ }^{18}$ F]GBR 13119 (1). The final product was purified by C-18 and silica gel SEP-PAKS, and analyzed by HPLC and TLC. Radiochemical purity was $>95 \%$, and chemical purity excellent (10-40 microgram amounts of $\mathrm{N}$-(2-hydroxyethyl)-N-(3-phenyl- 
propyl)piperazine were observed in some preparations). Specific activity, estimated by HPLC analysis at end of synthesis, was in excess of $2,000 \mathrm{Ci} / \mathrm{mmol}$ (limit of detection of UV detector utilized). Overall yields were 10-16\% (corrected for decay) in a total synthesis time of 120-140 minutes.

Preliminary in vivo study of regional brain distribution in mice shows striatal uptake $(2.4 \pm 1.2 \% \mathrm{ID} / \mathrm{g})$ and striatum/cerebellum ratios $(3.13 \pm 1.01)$ determined at $1 \mathrm{~h}$ which are essentially identical to those obtained with [18F]GBR 13119 (7). Further animal and human studies with this radiopharmaceutical will be reported in due course.

Acknowledgements. This work was supported by grants from the Department of Energy (DE-AC02-76EV02031) and the National Institutes of Health (NS-15655). We thank Phil Sherman and Teresa Pisani for performing the regional brain distributions, and Dr. B. Skrumsager of NOVO Industri A/S for a sample of GBR 12909.

\section{REFERENCES}

1. Haka M.S., Kilbourn M.R., Watkins G.L., and Toorongian S.A. - J. Labeled Compds. Radiopharm. 27:823-833 (1989).

2. Kilbourn M.R. and Haka M.S. - Appl. Radiat. Isot. 39:279-282 (1988).

3. Sogaard U., Michalow J., Butler B., Ingwersen S.H., Rafaelson J.O. - Psychopharm. 96: Abstract 31.02.29 (1988).

4. Andersen P.H. - Eur. J. Pharm. 166:493-504 (1989).

5. Van der Zee P., Koger H.S., Gootjes J., and Hespe W. - Eur. J. Med. Chem. 15:363383 (1980).

6. Mulholland G.K., Hichwa R.D., Kilbourn M.R., and Moskwa J. - J. Labeled Compds. Radiopharm. 26:192-193 (1989).

7. Kilbourn M.R., Haka M.S., Mulholland G.K., Sherman P.S., and Pisani T. - Eur. J. Pharm. 166:331-334 (1989). 